Article

\title{
Unique MicroRNA and mRNA Interactions in EGFR-Mutated Lung Adenocarcinoma
}

\author{
Sophia Subat ${ }^{1}$, Kentaro Inamura ${ }^{1, * \mathbb{C}}$, Hironori Ninomiya ${ }^{1}$, Hiroko Nagano ${ }^{1}$, \\ Sakae Okumura ${ }^{2}$ and Yuichi Ishikawa ${ }^{1}$ \\ 1 Division of Pathology, The Cancer Institute; Department of Pathology, The Cancer Institute Hospital, \\ Japanese Foundation for Cancer Research, 3-8-31 Ariake, Koto-ward, Tokyo 135-8550, Japan; \\ sophia.subat@jfcr.or.jp (S.S.); hironori.ninomiya@jfcr.or.jp (H.N.); hiroko.nagano@jfcr.or.jp (H.N.); \\ ishikawa@jfcr.or.jp (Y.I.) \\ 2 Department of Thoracic Surgical Oncology, The Cancer Institute Hospital, Japanese Foundation for Cancer \\ Research, 3-8-31 Ariake, Koto-ward, Tokyo 135-8550, Japan; sokumura@jfcr.or.jp \\ * Correspondence: kentaro.inamura@jfcr.or.jp; Tel.: +81-335-700-111 (ext. 5604)
}

Received: 5 October 2018; Accepted: 1 November 2018; Published: 6 November 2018

check for updates

\begin{abstract}
The EGFR gene was one of the first molecules to be selected for targeted gene therapy. EGFR-mutated lung adenocarcinoma, which is responsive to EGFR inhibitors, is characterized by a distinct oncogenic pathway in which unique microRNA (miRNA)-mRNA interactions have been observed. However, little information is available about the miRNA-mRNA regulatory network involved. Both miRNA and mRNA expression profiles were investigated using microarrays in 155 surgically resected specimens of lung adenocarcinoma with a known EGFR mutation status (52 mutated and 103 wild-type cases). An integrative analysis of the data was performed to identify the unique miRNA-mRNA regulatory network in EGFR-mutated lung adenocarcinoma. Expression profiling of miRNAs and mRNAs yielded characteristic miRNA/mRNA signatures (19 miRNAs/431 mRNAs) in EGFR-mutated lung adenocarcinoma. Five of the 19 miRNAs were previously listed as EGFR-mutation-specific miRNAs (i.e., miR-532-3p, miR-500a-3p, miR-224-5p, miR-502-3p, and miR-532-5p). An integrative analysis of miRNA and mRNA expression revealed a refined list of putative miRNA-mRNA interactions, of which 63 were potentially involved in $E G F R$-mutated tumors. Network structural analysis provided a comprehensive view of the complex miRNA-mRNA interactions in EGFR-mutated lung adenocarcinoma, including DUSP4 and MUC4 axes. Overall, this observational study provides insight into the unique miRNA-mRNA regulatory network present in EGFR-mutated tumors. Our findings, if validated, would inform future research examining the interplay of miRNAs and mRNAs in EGFR-mutated lung adenocarcinoma.
\end{abstract}

Keywords: driver mutation; EGFR; integrative association; messenger RNA; molecular-targeted therapy; noncoding RNA; non-small-cell lung carcinoma (NSCLC); precision medicine; tumorigenesis; tyrosine kinase inhibitor

\section{Introduction}

Globally, lung cancer is the leading cause of cancer-related deaths, resulting in more than one million deaths annually [1]. Lung cancer can be generally classified into small-cell lung carcinoma (SCLC; $20 \%$ of all lung cancers) and non-SCLC (NSCLC; 80\%), with adenocarcinoma representing the most prevalent subtype [2]. In lung adenocarcinoma, various mutations that drive cancer progression have emerged as druggable molecular targets [3-7]. Among them, EGFR mutation is the most prevalent genetic alterations, identifiable in $10-15 \%$ of Western and $30-40 \%$ of Asian populations [8-11]. Due to its frequent mutation, EGFR was one of the first molecules selected 
for targeted gene therapy [12]. Recent high-throughput techniques have substantially increased our knowledge of oncogenic mechanisms involved in EGFR-mutated adenocarcinoma. However, the mechanisms underlying its initiation and progression are not fully understood $[3,8,11]$.

MicroRNAs (miRNAs) are small noncoding RNAs composed of 18-25 nucleotides. Over the past decade, approximately 2000 human miRNAs have been identified [13]. Individual miRNAs have been shown to target a number of mRNAs and negatively regulate their expression by either inhibiting translation or inducing mRNA degradation, as each mRNA is regulated by multiple miRNAs [14-19]. Complex interactions between miRNAs and mRNAs play crucial roles in a variety of cellular processes, such as cellular differentiation, development, and tumorigenesis [16-21]. Aberrantly expressed miRNAs act either as tumor suppressors or enhancers in a context-dependent manner. Previous research has shown that miRNA-mRNA interactions differentially regulate the oncogenic processes involved in lung cancer according to the presence of driver mutations in the tumor [22-27]. In EGFR-mutated cancers, individual miRNA-mRNA interactions or miRNA/mRNA expression signatures have been characterized. However, no study has performed integrative analysis to investigate the complex miRNA-mRNA network in EGFR-mutated lung adenocarcinoma. Little information is available about the miRNA-mRNA regulatory network involved in this type of tumor.

In this study, we examined 155 surgically resected specimens of lung adenocarcinoma with a known EGFR mutation status (52 mutated and 103 wild-type cases) to identify the complex miRNA-mRNA regulatory network involved in this type of tumor. Using microarray and bioinformatics analyses, this study is the first comprehensive report of the miRNA-mRNA network present in EGFR-mutated lung adenocarcinoma.

\section{Materials and Methods}

\subsection{Clinical Samples}

We obtained lung adenocarcinoma tissue from 155 Japanese patients who underwent surgery at The Cancer Institute Hospital, Japanese Foundation for Cancer Research (JFCR), Tokyo, Japan, between April 1995 and January 2002. Informed consent was obtained from all patients, and the study protocol was approved by the Institutional Review Board of JFCR on 1 February 2018 (ethics code: 2012-1042). All tumor samples were dissected and snap-frozen in liquid nitrogen within $20 \mathrm{~min}$ of removal and stored at $-80^{\circ} \mathrm{C}$ until RNA extraction.

\subsection{EGFR Mutation}

For the mutational analysis of EGFR, DNA was extracted from fresh tumor specimens using a standard proteinase $\mathrm{K}$ digestion and phenol-chloroform extraction. The four exons that encode the tyrosine kinase domain of the EGFR gene (exons 18 to 21) were examined. We performed TaqMan ${ }^{\text {TM }}$ SNP Genotyping Assays (Applied Biosystems, Foster City, CA, USA) not only for exons 18 (G719X) and 21 (L858R and L861Q), but also for exon 20 (S768I and T790M) according to the manufacturer's instructions. Fragment analyses were conducted on the exon 19 deletion and exon 20 insertion, as previously described [28]. To investigate associations between EGFR mutations and clinicopathological factors, we used the Fisher's exact test. All two-sided $p$ values less than 0.05 were considered statistically significant.

\subsection{RNA Extraction}

Total RNAs were extracted from frozen tissue using miRNeasy Mini Kit (Qiagen, Hilden, Germany), according to the manufacturer's instructions. RNA concentration, purity, and integrity number (RIN) were measured using the 2100 Bioanalyzer (Agilent Technologies, Palo, CA, USA). Only samples with an RIN greater than 2.0 were selected for microarray hybridization. 


\subsection{Expression Analysis of MicroRNAs}

One-hundred nanograms of total RNA was labeled with cyanine-3-pCp, and then hybridized to an unrestricted human miRNA $8 \times 60 \mathrm{~K}$ microarray (release 19.0; Design ID 046064, Agilent Technologies), which covers 2042 human miRNAs, using Agilent's miRNA Complete Labeling Reagent and Hybridization Kit (5190-0456, Agilent Technologies). After hybridization, the arrays were washed and scanned at high resolution using the Agilent Microarray Scanner System (G2565CA, Agilent Technologies).

Raw miRNA expression data were processed using the Bioconductor package AgiMicroRna (Processing and Differential Expression Analysis of Agilent microRNA chips; Agilent Technologies) in R environment, version 3.5 [29,30]. In AgiMicroRna, the linear model features implemented in the limma package were used to assess differential gene expression [31,32]. The miRNA microarray data were normalized using the Robust Multi-Array Average approach, whereas undetected probes were flagged and filtered if detected in fewer than one-half of the array replicates. The miRNA datasets are accessible through Gene Expression Omnibus (GEO) accession number GSE119267. To identify differentially expressed miRNAs according to their EGFR mutation status, the limma package was used; miRNAs with $p$ values less than 0.05 and exhibiting differential expression according to their EGFR mutation status were selected.

\subsection{Expression Analysis of Messenger RNAs}

Fifty nanograms of total RNA was reverse-transcribed into cDNA and labeled using the Low Input Quick Amp Labeling Kit (5190-2305, Agilent Technologies), following the manufacturer's instructions. The cDNAs were hybridized to the SurePrint G3 Human Gene Expression $8 \times 60 \mathrm{~K}$ Microarray (Design ID 028004, Agilent Technologies). After hybridization, the arrays were washed using the Gene Expression Wash Buffer Kit (Agilent Technologies), according to the manufacturer's instructions. Scanning of the arrays was carried out using the Agilent Micro Scanner System (G2565CA, Agilent Technologies). Images and data were obtained using Agilent Feature Extraction Software, version 10.10.1.1 (Agilent Technologies).

Raw mRNA expression data were imported into R software, version 3.5. Background corrections were performed using the normexp method with an offset of 50, and quantiles were used for between-array normalization. Filtering of both controls and probes with low expression levels was performed by calculating the 95 percentiles of the negative control probes for each array. The datasets are accessible through GEO accession number GSE119268. To identify differentially expressed mRNAs according to their EGFR status, the limma package was used. Messenger RNAs with significant differences were selected with a fold change (FC) greater than 1.5 and a $p$ value of less than 0.05 .

\subsection{Integrative Analysis}

Integrated analyses of the miRNA and mRNA expression profiles were then carried out using differentially expressed miRNAs and mRNAs. MiRNA-mRNA correlations were identified using the miRComb package [33]. Pearson correlation coefficients between a particular miRNA and its predicted target mRNAs were computed and matched by target prediction using three databases: TargetScan, microCosm (formerly miRBase Targets), and miRDB [17,34,35]. Because miRNAs function as negative regulators, up- and downregulated miRNAs induce down- and upregulation of target mRNAs, respectively. We selected miRNA-mRNA pairs that were correlated in a negative manner $(p<0.01)$ and appeared in at least one of the three databases. The network was constructed and visualized with Cytoscape, version 3.6.1 (http://www.cytoscape.org). $p$ values from the Pearson correlation estimates were corrected for multiple testing using the Benjamini-Hochberg method. 


\subsection{Functional Analysis}

To identify the Kyoto Encyclopedia of Genes and Genomes (KEGG) pathways associated with select miRNAs, we used the union-of-pathways option of the bioinformatics prediction tool DNA Intelligent Analysis (DIANA)-miRPath software, version 3.0 [36]. To identify the biological pathways enriched by select mRNAs, we used the annotation tools from the Database for Annotation, Visualization, and Integrated Discovery (DAVID) Bioinformatics Resources, version 6.8 and selected categories with a $p$ value less than 0.05 and a fold enrichment greater than 2 [37].

\section{Results}

\subsection{Design of the Study and Clinicopathological Characteristics}

An overview of this study is outlined in Figure 1. We examined 155 surgically resected specimens of lung adenocarcinoma with a known EGFR mutation status (52 mutated and 103 wild-type cases). Table 1 summarizes the clinicopathological characteristics of the patients, stratified by EGFR status. EGFR mutation was associated with a no-to-moderate smoking history (pack-years $<40 ; p=0.02$ ) and a well-differentiated tumor $(p<0.0001)$.

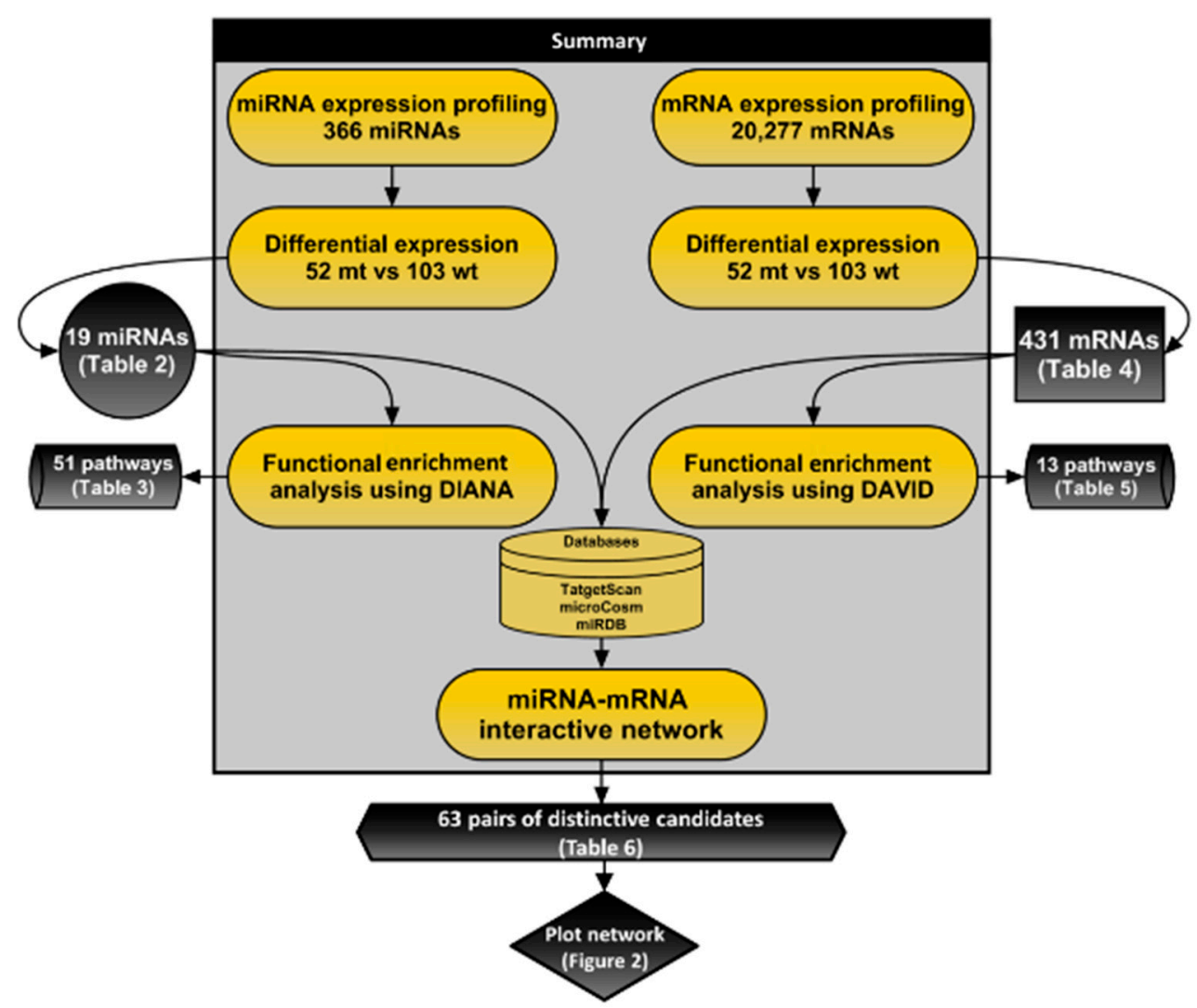

Figure 1. Flow diagram for predicting the target relationship between miRNA-mRNA pairs.

\subsection{Expression Profiling and Functional Analysis of MicroRNAs}

In an effort to identify miRNA expression signatures in EGFR-mutated tumors, we performed expression profiling of miRNAs. After filtering, the expression levels of 19 miRNAs were found to differ between the EGFR-mutated and wild-type groups, which consisted of 16 upregulated and three downregulated miRNAs (Table 2). Of note, five of these miRNAs were included in the previously reported 17-miRNA signature in EGFR-mutated lung adenocarcinoma: miR-532-3p, miR-500a-3p, miR-224-5p, miR-502-3p, and miR-532-5p [38]. 
Table 1. Clinicopathological characteristics of 155 cases of lung adenocarcinoma stratified by EGFR mutation status.

\begin{tabular}{|c|c|c|c|c|}
\hline \multirow[b]{2}{*}{ Variables } & \multirow{2}{*}{$\begin{array}{c}\text { Number of Patients } \\
(\%)\end{array}$} & \multicolumn{2}{|c|}{$E G F R$} & \multirow[b]{2}{*}{$p$ Values $^{1}$} \\
\hline & & $\begin{array}{c}\text { Mutation } \\
52(34 \%)\end{array}$ & $\begin{array}{l}\text { Wild-Type } \\
103(66 \%)\end{array}$ & \\
\hline Age (years) & & & & 0.30 \\
\hline$<65$ & $96(62 \%)$ & $29(56 \%)$ & $67(65 \%)$ & \\
\hline$\geq 65$ & $59(38 \%)$ & $23(44 \%)$ & $36(35 \%)$ & \\
\hline Gender & & & & 0.13 \\
\hline Males & $77(50 \%)$ & $21(40 \%)$ & $56(54 \%)$ & \\
\hline Females & $78(50 \%)$ & $31(60 \%)$ & $47(46 \%)$ & \\
\hline Smoking status & & & & 0.40 \\
\hline Never & $81(52 \%)$ & $30(58 \%)$ & $51(50 \%)$ & \\
\hline Ever & $74(48 \%)$ & $22(42 \%)$ & $52(50 \%)$ & \\
\hline Cumulative smoking & & & & 0.02 \\
\hline Pack-years $<40$ & $123(79 \%)$ & $47(90 \%)$ & $76(74 \%)$ & \\
\hline Pack-years $\geq 40$ & $32(21 \%)$ & $5(10 \%)$ & $24(26 \%)$ & \\
\hline Size $(\mathrm{mm})$ & & & & 0.23 \\
\hline$<30$ & $91(59 \%)$ & $27(52 \%)$ & $64(62 \%)$ & \\
\hline$\geq 30$ & $64(41 \%)$ & $25(48 \%)$ & $39(38 \%)$ & \\
\hline Tumor differentiation & & & & $<0.0001$ \\
\hline Well & $60(39 \%)$ & $37(72 \%)$ & $23(22 \%)$ & \\
\hline Moderate-poor & $95(61 \%)$ & $15(29 \%)$ & $80(78 \%)$ & \\
\hline Pathological stage & & & & 0.39 \\
\hline $\mathrm{I}$ & $93(60 \%)$ & $34(65 \%)$ & $59(57 \%)$ & \\
\hline II-IV & $62(40 \%)$ & $18(35 \%)$ & $44(43 \%)$ & \\
\hline
\end{tabular}

${ }^{1}$ The Fisher's exact test was used to calculate $p$ values.

Table 2. Nineteen miRNAs that were differentially expressed in EGFR-mutated compared to EGFR wild-type lung adenocarcinomas.

\begin{tabular}{cccc}
\hline miRNA & FC $^{\mathbf{1}}$ & $\boldsymbol{p}$ Values $^{\mathbf{2}}$ & Up or Down \\
\hline miR-532-3p & 3.52 & $1.32 \mathrm{E}-04$ & $\mathrm{Up}$ \\
miR-362-3p & 3.29 & $1.02 \mathrm{E}-04$ & $\mathrm{Up}$ \\
miR-340-5p & 3.25 & $3.44 \mathrm{E}-03$ & $\mathrm{Up}$ \\
miR-500a-3p & 2.93 & $1.32 \mathrm{E}-04$ & $\mathrm{Up}$ \\
miR-224-5p & 2.83 & $1.49 \mathrm{E}-02$ & $\mathrm{Up}$ \\
miR-362-5p & 2.82 & $1.04 \mathrm{E}-03$ & $\mathrm{Up}$ \\
miR-502-3p & 2.65 & $1.66 \mathrm{E}-03$ & $\mathrm{Up}$ \\
miR-590-5p & 2.37 & $1.33 \mathrm{E}-02$ & $\mathrm{Up}$ \\
miR-664a-3p & 2.31 & $4.86 \mathrm{E}-02$ & $\mathrm{Up}$ \\
miR-652-3p & 2.12 & $1.37 \mathrm{E}-02$ & $\mathrm{Up}$ \\
miR-532-5p & 2.05 & $1.91 \mathrm{E}-03$ & $\mathrm{Up}$ \\
miR-429 & 1.92 & $1.68 \mathrm{E}-02$ & $\mathrm{Up}$ \\
miR-660-5p & 1.70 & $1.14 \mathrm{E}-02$ & $\mathrm{Up}$ \\
miR-30e-5p & 1.38 & $3.44 \mathrm{E}-03$ & $\mathrm{Up}$ \\
miR-30c-5p & 1.34 & $3.09 \mathrm{E}-02$ & $\mathrm{Up}$ \\
miR-98-5p & 1.34 & $3.27 \mathrm{E}-02$ & $\mathrm{Up}$ \\
miR-6126 & -1.25 & $4.86 \mathrm{E}-02$ & Down \\
miR-3651 & -1.36 & $4.57 \mathrm{E}-02$ & Down \\
miR-223-3p & -1.66 & $1.37 \mathrm{E}-02$ & Down \\
\hline
\end{tabular}

FC, fold change. ${ }^{1}$ EGFR-mutated lung/EGFR wild-type lung adenocarcinoma; ${ }^{2} p$ values of the Pearson correlation estimate were corrected for multiple testing (Benjamini-Hochberg method applied).

Using DIANA-miRPath software, we investigated the characteristic biological processes in EGFR-mutated tumors based on miRNA expression. A total of 51 miRNA-involved processes were identified by a functional enrichment analysis (KEGG pathways; $p<0.05$, false discovery 
rate corrected). Supplementary Table S1 lists the characteristic biological processes enriched by 51 miRNAs that were differentially expressed according to EGFR mutation status. The top 30 biological pathways included the "Hippo signaling pathway (hsa04390)" ( $p=2.38 \mathrm{E}-08)$, "pathways in cancer (hsa05200)" ( $p=4.33 \mathrm{E}-05)$, and "non-small-cell lung cancer (hsa05223)" ( $p=3.75 \mathrm{E}-03)$, as shown in Table 3. "Pathways in cancer" was enriched in miRNAs, which included the five abovementioned concordant miRNAs [38].

Table 3. Top 30 biological pathways enriched by 19 differentially expressed miRNAs in EGFR-mutated compared to EGFR wild-type lung adenocarcinoma.

\begin{tabular}{|c|c|c|}
\hline KEGG Pathway & $p$ Values & $n^{1}$ of miRNAs \\
\hline Hippo signaling pathway & $2.38 \mathrm{E}-08$ & 18 \\
\hline Pathways in cancer & $4.33 \mathrm{E}-05$ & 18 \\
\hline FoxO signaling pathway & $2.38 \mathrm{E}-08$ & 17 \\
\hline Signaling pathways regulating pluripotency of stem cells & $3.84 \mathrm{E}-07$ & 17 \\
\hline PI3K-Akt signaling pathway & $2.44 \mathrm{E}-04$ & 17 \\
\hline Chronic myeloid leukemia & $4.43 \mathrm{E}-04$ & 17 \\
\hline Glioma & $9.11 \mathrm{E}-04$ & 17 \\
\hline T-cell receptor signaling pathway & $1.42 \mathrm{E}-03$ & 17 \\
\hline Regulation of actin cytoskeleton & $1.70 \mathrm{E}-03$ & 17 \\
\hline Neurotrophin signaling pathway & $2.80 \mathrm{E}-03$ & 17 \\
\hline Prolactin signaling pathway & $3.26 \mathrm{E}-03$ & 17 \\
\hline Viral carcinogenesis & $3.26 \mathrm{E}-03$ & 17 \\
\hline MAPK signaling pathway & $3.50 \mathrm{E}-03$ & 17 \\
\hline Non-small cell lung cancer & $3.75 \mathrm{E}-03$ & 17 \\
\hline Thyroid hormone signaling pathway & $3.79 \mathrm{E}-03$ & 17 \\
\hline cAMP signaling pathway & $4.95 \mathrm{E}-03$ & 17 \\
\hline Melanoma & $7.01 \mathrm{E}-03$ & 17 \\
\hline cGMP-PKG signaling pathway & $7.40 \mathrm{E}-03$ & 17 \\
\hline Dorsoventral axis formation & $1.99 \mathrm{E}-02$ & 17 \\
\hline Wnt signaling pathway & $2.59 \mathrm{E}-02$ & 17 \\
\hline B cell receptor signaling pathway & $2.80 \mathrm{E}-02$ & 17 \\
\hline Ubiquitin mediated proteolysis & $2.82 \mathrm{E}-02$ & 17 \\
\hline TGF-beta signaling pathway & $8.42 \mathrm{E}-08$ & 16 \\
\hline Proteoglycans in cancer & $1.36 \mathrm{E}-07$ & 16 \\
\hline Transcriptional misregulation in cancer & $3.26 \mathrm{E}-07$ & 16 \\
\hline Pancreatic cancer & $3.34 \mathrm{E}-05$ & 16 \\
\hline Ras signaling pathway & $8.22 \mathrm{E}-05$ & 16 \\
\hline ErbB signaling pathway & $1.12 \mathrm{E}-04$ & 16 \\
\hline GABAergic synapse & $3.59 \mathrm{E}-04$ & 16 \\
\hline Focal adhesion & $8.84 \mathrm{E}-04$ & 16 \\
\hline
\end{tabular}

KEGG, Kyoto Encyclopedia of Genes and Genomes. ${ }^{1} n$, number of miRNAs that enriched each biological pathway. Pathways with $p$ value less than 0.05 and thresholds for predictions greater than 0.8 are listed with the number of affected genes.

\subsection{Expression Profiling and Functional Enrichment Analysis of Messenger RNAs}

Using data from mRNA microarrays, we conducted expression profiling and functional enrichment analysis to identify mRNA expression signatures and enriched biological processes. After filtering, we identified 431 differentially expressed mRNAs that consisted of 270 upregulated and 161 downregulated mRNAs in EGFR-mutated tumors ( $p<0.05$ and FC $>1.5)$, as listed in Supplementary Table S2. A number of these mRNAs are known to be deregulated in NSCLC, including EGFR-mutated lung adenocarcinoma [39-43]. For example, our core mRNA signature included tumor-suppressor genes CDK6 and RB1 [39-42]. Moreover, the mRNA expression signature included DUSP4, EGFR, TNFRSF10B, and LRRC31, all of which were previously reported to be deregulated in EGFR-mutated tumors [43]. Table 4 lists the top 20 mRNAs that were differentially expressed between EGFR-mutated and wild-type tumors. 
Table 4. Top 20 mRNAs that were differentially expressed between EGFR-mutated compared to EGFR wild-type lung adenocarcinoma.

\begin{tabular}{cccc}
\hline mRNA & FC $^{\mathbf{1}}$ & $\boldsymbol{p ~}$ Values $^{\mathbf{2}}$ & Up or Down \\
\hline LRRC75B & 2.35 & $2.77 \mathrm{E}-13$ & $\mathrm{Up}$ \\
EGFR & 1.88 & $1.78 \mathrm{E}-11$ & $\mathrm{Up}$ \\
KIAA0319L & 1.65 & $2.08 \mathrm{E}-10$ & $\mathrm{Up}$ \\
CA10 & 2.75 & $2.31 \mathrm{E}-10$ & $\mathrm{Up}$ \\
USP13 & 1.82 & $2.31 \mathrm{E}-10$ & $\mathrm{Up}$ \\
CECR2 & 1.65 & $2.31 \mathrm{E}-10$ & $\mathrm{Up}$ \\
TBXT & 1.63 & $2.54 \mathrm{E}-10$ & $\mathrm{Up}$ \\
LCT & 1.83 & $5.56 \mathrm{E}-09$ & $\mathrm{Up}$ \\
MYBPHL & 3.44 & $6.00 \mathrm{E}-09$ & $\mathrm{Up}$ \\
GGTLC2 & 2.15 & $9.00 \mathrm{E}-09$ & $\mathrm{Up}$ \\
GGTLC1 & 2.77 & $1.47 \mathrm{E}-08$ & $\mathrm{Up}$ \\
FNDC10 & 2.51 & $1.74 \mathrm{E}-08$ & $\mathrm{Up}$ \\
ATP13A4 & 3.10 & $1.86 \mathrm{E}-08$ & $\mathrm{Up}$ \\
DDX21 & -1.60 & $2.41 \mathrm{E}-08$ & Down \\
SCUBE2 & 2.38 & $2.67 \mathrm{E}-08$ & $\mathrm{Up}$ \\
APOH & 3.24 & $1.40 \mathrm{E}-07$ & $\mathrm{Up}$ \\
SERPINA3 & -3.89 & $1.49 \mathrm{E}-07$ & Down \\
GFRA3 & 2.85 & $1.58 \mathrm{E}-07$ & $\mathrm{Up}$ \\
MEGF6 & 1.88 & $1.58 \mathrm{E}-07$ & $\mathrm{Up}$ \\
SLC41A1 & 1.67 & $1.95 \mathrm{E}-07$ & $\mathrm{Up}$ \\
\hline
\end{tabular}

${ }^{1}$ EGFR-mutated lung/EGFR wild-type lung adenocarcinoma; ${ }^{2} p$ value of the Pearson correlation estimate was corrected for multiple testing (Benjamini-Hochberg method applied).

To investigate the potential biological functional relevance of the differentially expressed mRNAs, we performed functional enrichment analysis using DAVID pathways. Table 5 lists the top 13 KEGG pathways enriched by the 431 mRNAs that were differentially expressed according to EGFR status, providing an idea of which pathways were significantly enriched in EGFR-mutated tumors. Highly enriched pathways included "pathways in cancer" ( $p=4.07 \mathrm{E}-03)$, "Wnt signaling pathway" ( $p=4.30 \mathrm{E}-02)$, "small-cell lung cancer" ( $p=4.88 \mathrm{E}-02)$, and "non-small-cell lung cancer" $(p=4.17 \mathrm{E}-02)$. The "nonsmall-cell lung cancer" pathway was enriched by mRNAs, including EGFR, RB1, and CDK6, all known to be associated with tumorigenesis in NSCLC $[3,42,44]$.

Table 5. Biologic pathways enriched by 431 differentially expressed mRNAs in EGFR-mutated compared to EGFR wild-type lung adenocarcinomas.

\begin{tabular}{llll}
\hline KEGG_PATHWAY & $p$ Values & $n^{\mathbf{1}}$ & Genes \\
\hline Pathways in cancer & $4.70 \mathrm{E}-03$ & 19 & COL4A4,FZD9,EGFR,CEBPA,COL4A3,FGFR3,PTGS2,BRAF,EGLN3,CDK6, \\
Protein digestion and absorption & $1.00 \mathrm{E}-03$ & 9 & COL4A4,COL4A3,COL21A1,COL7A1,KCNK5,PRSS3,PRSS1,DPP4,KCNE3 \\
Arachidonic acid metabolism & $5.69 \mathrm{E}-04$ & 8 & AKR1C3,GPX2,PTGS2,CYP2B6,CYP2C9,ALOX15B,PLA2G1B,GGT1 \\
Hepatitis C & $3.64 \mathrm{E}-02$ & 8 & EGFR,OCLN,BRAF,CLDN3,SOCS3,CLDN2,CLDN10,OAS1 \\
Wnt signaling pathway & $4.30 \mathrm{E}-02$ & 8 & FZD9,FZD10,WNT3,DKK1,CCND2,VANGL2,BAMBI,DAAM2 \\
Central carbon metabolism in cancer & $3.69 \mathrm{E}-03$ & 7 & GLS2,EGFR,FGFR3,GLS,SLC2A1,PFKP,PGAM2 \\
Small-cell lung cancer & $4.88 \mathrm{E}-02$ & 6 & COL4A4,COL4A3,PTGS2,CDK6,RB1,BIRC3 \\
Bladder cancer & $1.50 \mathrm{E}-02$ & 5 & EGFR,FGFR3,BRAF,RB1,DAPK2 \\
Non-small-cell lung cancer & $4.17 \mathrm{E}-02$ & 5 & EGFR,BRAF,CDK6,RB1,ALK \\
Nicotinate and nicotinamide metabolism & $2.96 \mathrm{E}-02$ & 4 & NT5M,ENPP3,QPRT,NNMT \\
Galactose metabolism & $3.23 \mathrm{E}-02$ & 4 & AKR1B10,AKR1B1,PFKP,LCT \\
Fructose and mannose metabolism & $3.82 \mathrm{E}-02$ & 4 & GMPPB,AKR1B10,AKR1B1,PFKP \\
Alanine, aspartate and glutamate metabolism & $4.79 \mathrm{E}-02$ & 4 & GLS2,GLS,CPS1,RIMKLA \\
\hline
\end{tabular}

${ }^{1} n$, number of mRNAs that enriched each biological pathway. Pathways with $p$ value less than 0.05 and fold enrichment greater than 2 are listed with the number of affected genes.

\subsection{MiRNA-mRNA Interactive Network}

To identify miRNA-mRNA interactions, we applied the miRComb package using miRNAs and mRNAs whose expression levels differed significantly in each dataset [45]. First, we identified a total of 149 miRNA-mRNAs pairs that showed negative correlations according to three miRNA target 
prediction databases: TargetScan, microcosm, and miRDB (Supplementary Table S3). To determine whether different miRNAs within an miRNA-mRNA signature interact with the same target genes, we performed network analysis using Cytoscape. Figure 2A shows all 149 miRNA-mRNA interactions, and Figure 2B represents the statistically significant miRNA-mRNA interactive network present in EGFR-mutated tumors (63 miRNA-mRNA interactions; $p<0.01$ ). Table 6 lists the top 20 miRNA-mRNA pairs sorted by false discovery rate. Upregulated miR-30c-5p and downregulated miR-223-3p shared most of their target mRNAs. Interestingly, miR-532-5p and miR-532-3p, which belong to the same miR-532 family and are included in the enriched "pathways in cancer", were located close to each other in the interactive network (Figure 2B). MUC4, the downregulation of which is associated with tumor progression in EGFR-mutated lung adenocarcinoma, was targeted by three miRNAs: miR-500a-3p, miR-502-3p, and miR-652-3p [46]. (Figure 2B and Supplementary Table S4).

A

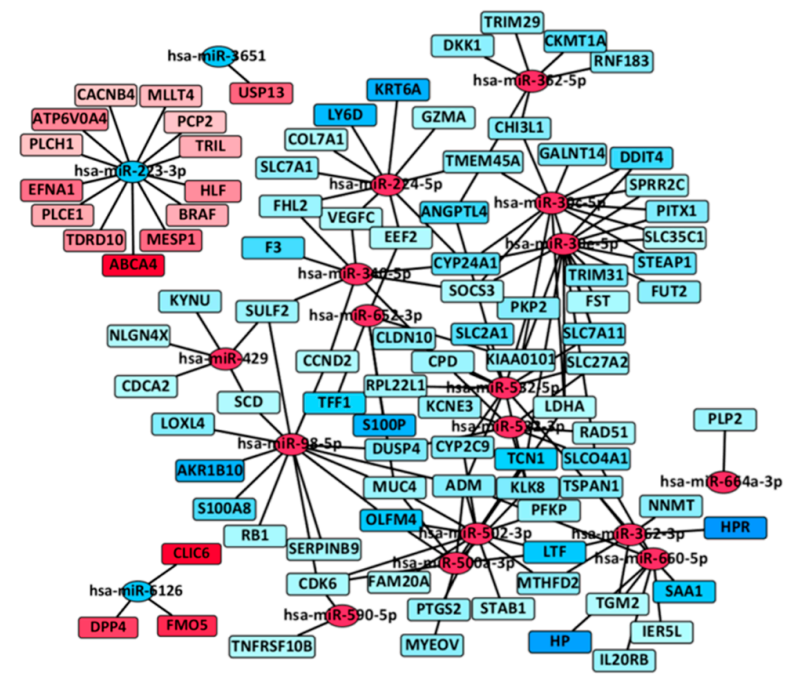

B

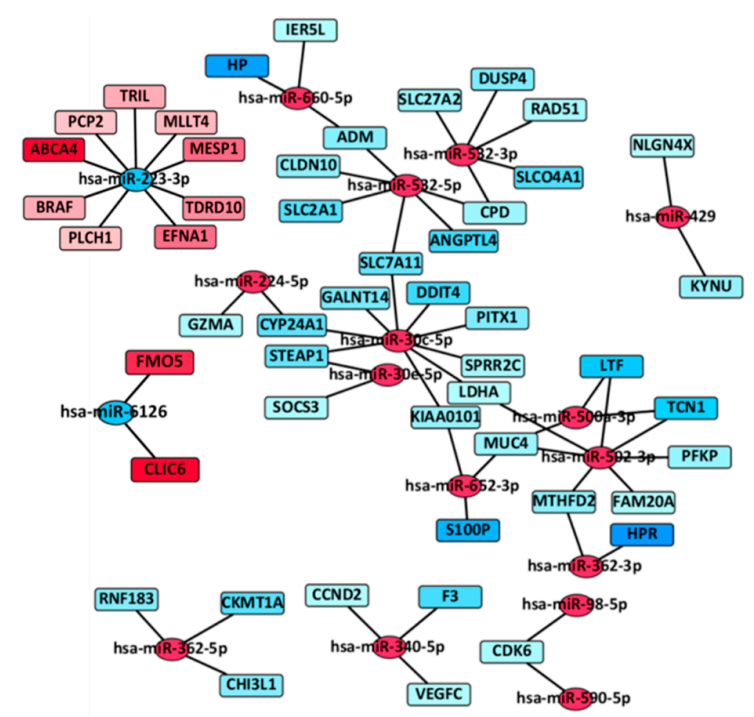

Figure 2. MiRNA-mRNA interactive network in EGFR-mutant lung adenocarcinoma. (A) Network of 149 miRNA-mRNA interactions in EGFR-mutated lung adenocarcinoma; (B) Network of 63 statistically significant miRNA-mRNA interactions in EGFR-mutated lung adenocarcinoma $(p<0.01)$. Circles and squares represent miRNAs and mRNAs, respectively. Red indicates an upregulated miRNA or mRNA, whereas blue indicates a downregulated miRNA or mRNA. A line indicates an miRNA-mRNA interaction. The color intensity is proportional to the fold change (continuous) of EGFR-mutated/wild-type lung adenocarcinoma. 
Table 6. Top 20 significant miRNA-mRNA interaction pairs.

\begin{tabular}{ccccc}
\hline miRNA & FC_miRNA $^{\mathbf{1}}$ & mRNA & FC_mRNA $^{\mathbf{1}}$ & FDR \\
\hline miR-502-3p & $\mathrm{Up}$ & MTHFD2 & Down & $1.00 \mathrm{E}-09$ \\
miR-502-3p & $\mathrm{Up}$ & LTF & Down & $1.20 \mathrm{E}-07$ \\
miR-502-3p & $\mathrm{Up}$ & PFKP & Down & $2.11 \mathrm{E}-07$ \\
miR-30c-5p & $\mathrm{Up}$ & GALNT14 & Down & $5.85 \mathrm{E}-07$ \\
miR-30c-5p & $\mathrm{Up}$ & STEAP1 & Down & $6.07 \mathrm{E}-07$ \\
miR-532-3p & $\mathrm{Up}$ & CPD & Down & $7.25 \mathrm{E}-07$ \\
miR-502-3p & $\mathrm{Up}$ & LDHA & Down & $9.39 \mathrm{E}-07$ \\
miR-223-3p & Down & BRAF & Up & $1.36 \mathrm{E}-06$ \\
miR-6126 & Down & CLIC6 & Up & $1.92 \mathrm{E}-06$ \\
miR-30c-5p & $\mathrm{Up}$ & KIAA0101 & Down & $3.04 \mathrm{E}-06$ \\
miR-532-5p & $\mathrm{Up}$ & CPD & Down & $3.19 \mathrm{E}-06$ \\
miR-532-3p & $\mathrm{Up}$ & RAD51 & Down & $5.83 \mathrm{E}-06$ \\
miR-532-3p & $\mathrm{Up}$ & DUSP4 & Down & $6.70 \mathrm{E}-06$ \\
miR-500a-3p & $\mathrm{Up}$ & LTF & Down & $1.17 \mathrm{E}-05$ \\
miR-502-3p & $\mathrm{Up}$ & MUC4 & Down & $1.71 \mathrm{E}-05$ \\
miR-223-3p & Down & PLCH1 & Up & $1.79 \mathrm{E}-05$ \\
miR-532-5p & $\mathrm{Up}$ & ANGPTL4 & Down & $1.83 \mathrm{E}-05$ \\
miR-532-5p & $\mathrm{Up}$ & CLDN10 & Down & $2.02 \mathrm{E}-05$ \\
miR-6126 & Down & FMO5 & Up & $2.57 \mathrm{E}-05$ \\
miR-660-5p & $\mathrm{Up}$ & IER5L & Down & $3.69 \mathrm{E}-05$ \\
\hline
\end{tabular}

FDR, false discovery rate. ${ }^{1}$ EGFR-mutated lung/EGFR wild-type lung adenocarcinoma.

\section{Discussion}

We examined surgically resected cases of EGFR-mutated (52 cases) and wild-type (103 cases) lung adenocarcinoma, and identified the unique miRNA-mRNA regulatory network present in EGFR-mutated tumors (Figure 1). Our findings, if validated, would identify a list of miRNA-mRNA interactions that could be used to understand the molecular pathogenesis of EGFR-mutated lung adenocarcinoma.

Lung cancer represents a group of molecularly heterogeneous tumors with different miRNA and mRNA expression signatures $[14,16,22,23,47,48]$. Numerous studies have previously reported genotype-specific miRNA and mRNA signatures in lung adenocarcinoma [38,43,49-51]. However, these signatures vary considerably and have few genes in common because of the different study populations, microarray platforms, and analytic methods utilized [52]. In EGFR-mutated lung adenocarcinoma, Bjaanæs et al. and Chitale et al. demonstrated characteristic miRNA and mRNA signatures, respectively; however, no studies have validated their results $[38,43]$; In the current study, we identified the 19-miRNA and 431-mRNA expression signatures in EGFR-mutated tumors. Typical miRNAs in the 19-miRNA signature include high expression levels of miR-532-3p, miR362-3p, miR-340-5p, miR-500a-3p, miR-224-5p, miR-502-3p, and miR-532-5p, and low expression levels of miR-223-3p, all related with tumorigenesis or tumor progression in NSCLC $[38,49,51,53,54]$. High expression levels of miR-224 and low expression levels of miR-223 have been previously reported to promote tumor progression in lung cancer [53,54]. Of note, five of the 19 miRNAs were also included in the previously reported 17-miRNA expression signature in EGFR-mutated lung adenocarcinoma [38]. Similarly, our mRNA expression signature in EGFR-mutated tumors included DUSP4, EGFR, TNFRSF10B, and LRRC3, all reportedly deregulated in EGFR-mutated lung adenocarcinoma [43]. Taken together, our results are concordant with previous findings, which enhance the credibility of our findings.

Accumulating evidence has led to the identification of characteristic oncogenic and biological processes in EGFR-mutated or -deregulated tumors [11,55-57]. EGFR aberrations activate multiple downstream pro-oncogenic signaling pathways and subsequently induce biological processes that are beneficial to cancer maintenance and progression, including chronic initiation, metabolic regulation, and cell-cycle regulation [58]. We identified the oncogenic or biological processes that were 
characteristically observed in EGFR-mutated lung adenocarcinoma on the basis of miRNA and mRNA expression levels. Interestingly, the miRNA expression signature indicates that the Hippo signaling pathway may be deregulated in EGFR-mutated tumors. The Hippo pathway is a kinase cascade stimulated by the YAP1 oncogene, the activation of which is associated with resistance to EGFR inhibitors in EGFR-mutated lung adenocarcinoma [59-61]. The Hippo pathway appears to be characteristically deregulated in EGFR-mutated tumors and may thus serve as a therapeutic target. On the other hand, analysis of mRNA expression levels yielded the existence of the "pathways in cancer" and "non-small-cell lung cancer" pathways, which were enriched in EGFR-mutated tumors. Both of these pathways predictably lead to high expression levels of EGFR mRNA, given that EGFR amplification frequently promotes tumor invasion in EGFR-mutated lung adenocarcinoma [62]. The enriched "non-small-cell lung cancer" pathway included downregulated RB1 and CDK6, well-known tumor suppressors that regulate cell division and the cell cycle. Collectively, these results help define the mechanisms that underlie tumor initiation or progression in EGFR-mutated lung adenocarcinoma.

EGFR-mutated lung adenocarcinoma is orchestrated by complex miRNA-mRNA interactions. Much work has investigated miRNA/mRNA expression signatures and associations between a specific miRNA and target mRNAs in tumorigenic processes in EGFR-mutated tumors [11,14,16-18,23,48,63-66]. However, no study has comprehensively analyzed complex miRNA-mRNA interactions in EGFR-mutated tumors. Typical interactions included miRNA-532-3p/RAD51 and miRNA-5323p/DUSP4 interactions. Zhong et al. reported that the mutated EGFR mediates the role of RAD51 in regulating radiation-induced cell-cycle arrest [67]. Chitale et al. reported that EGFR-mutated lung adenocarcinoma was strongly associated with low expression levels of DUSP4 [43]. These findings suggest that miR-532-3p functions as an oncogenic miRNA by downregulating the tumor suppressors RAD51 and DUSP4. Additionally, complex interactions between upregulated miR-500a-3p, miR-502-3p, and miR-652-3p, and downregulated MUC4 were identified in EGFR-mutated tumors. Downregulated MUC4 has been reported to induce tumor progression in conjunction with an EGFR mutation [46]. Taken together, the concordant results in this and previous studies help identify characteristic oncogenic pathways in EGFR-mutated lung adenocarcinoma.

This study had limitations. First, its observational nature precludes the determination of a causal association between an individual miRNA and its target mRNAs. Certain mechanisms of gene regulation might be due to indirect effects by other modulators, such as transcription factors. Therefore, further research is required to mechanistically validate the interactions predicted by our results. Second, we did not investigate $K R A S, A L K$, or other driver mutations. Therefore, it would be necessary to confirm that miRNA-mRNA interactions identified in this study are truly associated with EGFR status. Third, clinicopathological variables might confound miRNA-mRNA interactions. Finally, no validation study was performed. Nonetheless, our results are concordant with previous observations, which enhance the credibility of our findings [38,43]. Further investigations with a larger sample size and other races are warranted to confirm our findings.

\section{Conclusions}

In summary, we identified the unique miRNA-mRNA interactions in EGFR-mutated lung adenocarcinoma. To our knowledge, this is the first study to identify the unique miRNA-mRNA network involved in EGFR-mutated lung adenocarcinoma. Our findings, if validated, would inform future research examining the interplay between miRNAs and mRNAs in EGFR-mutated lung adenocarcinoma.

Supplementary Materials: The following are available online at http:/ /www.mdpi.com/2077-0383/7/11/419/s1, Table S1: Pathway mapping of differentially expressed miRNAs, Table S2: 431 mRNAs that were significant differentially expressed between EGFR-mutated and EGFR-wild tumors, Table S3: miRNA-mRNA interactions predicted by miRComb, Table S4: Characteristics of patients and tumors included in the microarray.

Author Contributions: K.I., S.S., and Y.I. conceived and designed the study. K.I., H.N. (Hironori Ninomiya), H.N. (Hiroko Nagano), S.O., and Y.I. contributed to the acquisition of clinical and tumor tissue data. S.S. and K.I. performed data analyses. S.S. and K.I. contributed to the interpretation of the findings. S.S. and K.I. drafted the manuscript. All authors contributed revisions and read and approved the final draft. 
Funding: This research was funded by JSPS KAKENHI Grant Numbers JP16K08679 (K.I.), JP26430149 (H.Ni.), and JP15H04714 (Y.I.), as well as partly by the Smoking Research Foundation.

Acknowledgments: The authors thank Motoyoshi Iwakoshi, Miyuki Kogure, Tomoyo Kakita, and Kimie Nomura for their technical assistance, and Yuki Takano and Chikako Yoshida for their secretarial expertise.

Conflicts of Interest: K.I. received a research grant from Konica Minolta, Inc. Y.I. received research grants from Daiichi Sankyo Co. Ltd., Chugai Pharmaceutical Co. Ltd., and Sony Corp., and is a consultant for Fujirebio Inc. All other authors declare no conflict of interest.

\section{References}

1. Siegel, R.L.; Miller, K.D.; Jemal, A. Cancer statistics, 2018. CA Cancer J. Clin. 2018, 68, 7-30. [CrossRef] [PubMed]

2. Inamura, K. Lung cancer: Understanding its molecular pathology and the 2015 WHO classification. Front. Oncol. 2017, 7, 1-7. [CrossRef] [PubMed]

3. Paez, J.G.; Jänne, P.; Lee, J.C.; Tracy, S.; Greulich, H.; Gabriel, S.; Herman, P.; Kaye, F.J.; Lindeman, N.; Boggon, T.J.; et al. EGFR mutations in lung cancer: Correlation with clinical response to gefitinib therapy. Science 2004, 304, 1497-1500. [CrossRef] [PubMed]

4. Shaw, A.T.; Hsu, P.P.; Awad, M.M.; Engelman, J.A. Tyrosine kinase gene rearrangements in epithelial malignancies. Nat. Rev. Cancer 2013, 13, 772-787. [CrossRef] [PubMed]

5. Hallberg, B.; Palmer, R.H. Mechanistic insight into ALK receptor tyrosine kinase in human cancer biology. Nat. Rev. Cancer 2013, 13, 685-700. [CrossRef] [PubMed]

6. Takeuchi, K.; Soda, M.; Togashi, Y.; Suzuki, R.; Sakata, S.; Hatano, S.; Asaka, R.; Hamanaka, W.; Ninomiya, H.; Uehara, H.; et al. RET, ROS1 and ALK fusions in lung cancer. Nat. Med. 2012, 18, 378-381. [CrossRef] [PubMed]

7. Soda, M.; Choi, Y.L.; Enomoto, M.; Takada, S.; Yamashita, Y.; Ishikawa, S.; Fujiwara, S.I.; Watanabe, H.; Kurashina, K.; Hatanaka, H.; et al. Identification of the transforming EML4-ALK fusion gene in non-small-cell lung cancer. Nature 2007, 448, 561-566. [CrossRef] [PubMed]

8. Yun Ha, S.; Choi, S.-J.; Ho Cho, J.; Joo Choi, H.; Lee, J.; Jung, K.; Irwin, D.; Liu, X.; Lira, M.E.; Mao, M.; et al. Lung cancer in never-smoker Asian females is driven by oncogenic mutations, most often involving EGFR. Oncotarget 2015, 6, 5465-5474.

9. Inamura, K.; Ninomiya, H.; Ishikawa, Y.; Matsubara, O. Is the epidermal growth factor receptor status in lung cancers reflected in clinicopathologic features? Arch. Pathol. Lab. Med. 2010, 134, 66-72. [PubMed]

10. Veale, D.; Ashcroft, T.; Marsh, C.; Gibson, G.J.; Harris, A.L. Epidermal growth factor receptors in non-small cell lung cancer. Br. J. Cancer 1987, 55, 513-516. [CrossRef] [PubMed]

11. Sharma, S.V.; Bell, D.W.; Settleman, J.; Haber, D.A. Epidermal growth factor receptor mutations in lung cancer. Nat. Rev. Cancer 2007, 7, 169-181. [CrossRef] [PubMed]

12. Brambilla, E.; Gazdar, A. Pathogenesis of lung cancer signalling pathways: Roadmap for therapies. Eur. Respir. J. 2009, 33, 1485-1497. [CrossRef] [PubMed]

13. Lee, Y.S.; Dutta, A. MicroRNAs in Cancer. Annu. Rev. Pathol. Mech. Dis. 2009, 4, 199-227. [CrossRef] [PubMed]

14. Calin, G.A.; Croce, C.M. MicroRNA signatures in human cancers. Nat. Rev. Cancer 2006, 6, 857-866. [CrossRef] [PubMed]

15. Hayes, J.; Peruzzi, P.P.; Lawler, S. MicroRNAs in cancer: Biomarkers, functions and therapy. Trends Mol. Med. 2014, 20, 460-469. [CrossRef] [PubMed]

16. Lewis, B.P.; Shih, I.H.; Jones-Rhoades, M.W.; Bartel, D.P.; Burge, C.B. Prediction of mammalian microRNA targets. Cell 2003, 115, 787-798. [CrossRef]

17. Lewis, B.P.; Burge, C.B.; Bartel, D.P. Conserved seed pairing, often flanked by adenosines, indicates that thousands of human genes are microRNA targets. Cell 2005, 120, 15-20. [CrossRef] [PubMed]

18. John, B.; Enright, A.J.; Aravin, A.; Tuschl, T.; Sander, C.; Marks, D.S. Human microRNA targets. PLoS Biol. 2004, 2. [CrossRef] [PubMed]

19. Rajewsky, N. MicroRNA target predictions in animals. Nat. Genet. 2006, 38, 8-13. [CrossRef] [PubMed]

20. Inamura, K.; Ishikawa, Y. MicroRNA in lung cancer: Novel biomarkers and potential tools for treatment. J. Clin. Med. 2016, 5, 36. [CrossRef] [PubMed] 
21. Hwang, H.W.; Mendell, J.T. MicroRNAs in cell proliferation, cell death, and tumorigenesis. Br. J. Cancer 2006, 94, 776-780. [CrossRef] [PubMed]

22. Garzon, R.; Fabbri, M.; Cimmino, A.; Calin, G.A.; Croce, C.M. MicroRNA expression and function in cancer. Trends Mol. Med. 2006, 12, 580-587. [CrossRef] [PubMed]

23. Iorio, M.V.; Croce, C.M. MicroRNA dysregulation in cancer: Diagnostics, monitoring and therapeutics. A comprehensive review. EMBO Mol. Med. 2012, 4, 143-159. [CrossRef] [PubMed]

24. Kan, Z.; Jaiswal, B.S.; Stinson, J.; Janakiraman, V.; Bhatt, D.; Stern, H.M.; Yue, P.; Haverty, P.M.; Bourgon, R.; Zheng, J.; et al. Diverse somatic mutation patterns and pathway alterations in human cancers. Nature 2010, 466, 869-873. [CrossRef] [PubMed]

25. Esquela-Kerscher, A.; Slack, F.J. Oncomirs-MicroRNAs with a role in cancer. Nat. Rev. Cancer 2006, 6, 259-269. [CrossRef] [PubMed]

26. Ryan, B.M.; Robles, A.I.; Harris, C.C. Genetic variation in microRNA networks: The implications for cancer research. Nat. Rev. Cancer 2011, 10, 389-402. [CrossRef] [PubMed]

27. Zhao, X.M.; Liu, K.Q.; Zhu, G.; He, F.; Duval, B.; Richer, J.M.; Huang, D.S.; Jiang, C.J.; Hao, J.K.; Chen, L. Identifying cancer-related microRNAs based on gene expression data. Bioinformatics 2015, 31, 1226-1234. [CrossRef] [PubMed]

28. Inamura, K.; Togashi, Y.; Nomura, K.; Ninomiya, H.; Hiramatsu, M.; Okui, M.; Satoh, Y.; Okumura, S.; Nakagawa, K.; Tsuchiya, E.; et al. Up-regulation of PTEN at the transcriptional level is an adverse prognostic factor in female lung adenocarcinomas. Lung Cancer 2007, 57, 201-206. [CrossRef] [PubMed]

29. Gentleman, R.C.; Carey, V.J.; Bates, D.M.; Bolstad, B.; Dettling, M.; Dudoit, S.; Ellis, B.; Gautier, L.; Ge, Y.; Gentry, J.; et al. Bioconductor: Open software development for computational biology and bioinformatics. Genome Biol. 2004, 5. [CrossRef] [PubMed]

30. López-Romero, P. Pre-processing and differential expression analysis of Agilent microRNA arrays using the AgiMicroRNA Bioconductor library. BMC Genomics 2011, 12. [CrossRef] [PubMed]

31. Smyth, G.K. Linear models and empirical bayes methods for assessing differential expression in microarray experiments. Stat. Appl. Genet. Mol. Biol. 2004, 3, 1-25. [CrossRef] [PubMed]

32. Smyth, G.K. Limma: Linear Models for Microarray Data; Springer: New York, CA, USA, 2005; pp. $397-420$.

33. Vila-casadesús, M.; Gironella, M. MiRComb: An R package to analyse miRNA-mRNA interactions. Package'miRComb'. 2016. Available online: http:/ / mircomb.sourceforge.net (accessed on 5 July 2018).

34. Rehmsmeier, M.; Steffen, P.; Höchsmann, M.; Giegerich, R.; Ho, M. Fast and effective prediction of microRNA/target duplexes. Spring 2004, 1507-1517. [CrossRef] [PubMed]

35. Wong, N.; Wang, X. MiRDB: An online resource for microRNA target prediction and functional annotations. Nucleic Acids Res. 2015, 43, 146-152. [CrossRef] [PubMed]

36. Vlachos, I.S.; Zagganas, K.; Paraskevopoulou, M.D.; Georgakilas, G.; Karagkouni, D.; Vergoulis, T.; Dalamagas, T.; Hatzigeorgiou, A.G. DIANA-miRPath v3.0: Deciphering microRNA function with experimental support. Nucleic Acids Res. 2015, 43, 460-466. [CrossRef] [PubMed]

37. Huang, D.W.; Sherman, B.T.; Tan, Q.; Kir, J.; Liu, D.; Bryant, D.; Guo, Y.; Stephens, R.; Baseler, M.W.; Lane, H.C.; Lempicki, R. A DAVID bioinformatics resources: Expanded annotation database and novel algorithms to better extract biology from large gene lists. Nucleic Acids Res. 2007, 35, 169-175. [CrossRef] [PubMed]

38. Bjaanæs, M.M.; Halvorsen, A.R.; Solberg, S.; Jørgensen, L.; Dragani, T.A.; Galvan, A.; Colombo, F.; Anderlini, M.; Pastorino, U.; Kure, E.; et al. Unique microRNA-profiles in EGFR-mutated lung adenocarcinomas. Int. J. Cancer 2014, 135, 1812-1821. [CrossRef] [PubMed]

39. Ouelle, D.E.; Zindy, F.; Ashmun, R.A.; Sherr, C.J. Alternative reading frames of the INK4a tumor suppressor gene encode two unrelated proteins capable of inducing cell cycle arrest. Cell 1995, 83, 993-1000. [CrossRef]

40. Ding, L.; Getz, G.; Wheeler, D.A.; Mardis, E.R.; McLellan, M.D.; Cibulskis, K.; Sougnez, C.; Greulich, H.; Muzny, D.M.; Morgan, M.B.; et al. Somatic mutations affect key pathways in lung adenocarcinoma. Nature 2008, 455, 1069-1075. [CrossRef] [PubMed]

41. Hida, T.; Yatabe, Y.; Achiwa, H.; Muramatsu, H.; Kozaki, K.; Nakamura, S.; Ogawa, M.; Mitsudomi, T.; Sugiura, T.; Takahashi, T. Increased expression of cyclooxygenase 2 occurs frequently in human lung cancers, specifically in adenocarcinomas. Cancer Res. 1998, 3761-3764.

42. Patnaik, A.; Rosen, L.S.; Tolaney, S.M.; Tolcher, A.W.; Goldman, J.W.; Gandhi, L.; Papadopoulos, K.P.; Beeram, M.; Rasco, D.W.; Hilton, J.F.; et al. Efficacy and safety of Abemaciclib, an inhibitor of CDK4 and 
CDK6, for patients with breast cancer, non-small cell lung cancer, and other solid tumors. Cancer Discov. 2016, 6, 740-753. [CrossRef] [PubMed]

43. Chitale, D.; Gong, Y.; Taylor, B.S.; Broderick, S.; Brennan, C.; Somwar, R.; Golas, B.; Wang, L.; Motoi, N.; Szoke, J.; et al. An integrated genomic analysis of lung cancer reveals loss of DUSP4 in EGFR-mutant tumors. Oncogene 2009, 28, 2773-2783. [CrossRef] [PubMed]

44. Liu, F.; Cai, Y.; Rong, X.; Chen, J.; Zheng, D.; Chen, L.; Zhang, J.; Luo, R.; Zhao, P.; Ruan, J. MiR-661 promotes tumor invasion and metastasis by directly inhibiting RB1 in non-small cell lung cancer. Mol. Cancer 2017, 16, 122. [CrossRef] [PubMed]

45. Vila-Casadesús, M.; Gironella, M.; Lozano, J.J. MiRComb: An R package to analyse miRNA-mRNA interactions. Examples across five digestive cancers. PLoS ONE 2016, 11, e0151127. [CrossRef] [PubMed]

46. Rokutan-Kurata, M.; Yoshizawa, A.; Sumiyoshi, S.; Sonobe, M.; Menju, T.; Momose, M.; Koyama, M.; Shigeto, S.; Fujimoto, M.; Zhang, M.; et al. Lung adenocarcinoma with MUC4 expression is associated with smoking status, HER2 protein expression, and poor prognosis: Clinicopathologic analysis of 338 cases. Clin. Lung Cancer 2017, 18, 273-281. [CrossRef] [PubMed]

47. Lu, J.; Getz, G.; Miska, E.A.; Alvarez-Saavedra, E.; Lamb, J.; Peck, D.; Sweet-Cordero, A.; Ebert, B.L.; Mak, R.H.; Ferrando, A.A.; et al. MicroRNA expression profiles classify human cancers. Nature 2005, 435, 834-838. [CrossRef] [PubMed]

48. Volinia, S.; Calin, G.A.; Liu, C.-G.; Ambs, S.; Cimmino, A.; Petrocca, F.; Visone, R.; Iorio, M.; Roldo, C.; Ferracin, M.; et al. A microRNA expression signature of human solid tumors defines cancer gene targets. Proc. Natl. Acad. Sci. USA 2006, 103, 2257-2261. [CrossRef] [PubMed]

49. Yanaihara, N.; Caplen, N.; Bowman, E.; Seike, M.; Kumamoto, K.; Yi, M.; Stephens, R.M.; Okamoto, A.; Yokota, J.; Tanaka, T.; et al. Unique microRNA molecular profiles in lung cancer diagnosis and prognosis. Cancer Cell 2006, 9, 189-198. [CrossRef] [PubMed]

50. Pak, M.G.; Lee, C.H.; Lee, W.J.; Shin, D.H.; Roh, M.S. Unique microRNAs in lung adenocarcinoma groups according to major TKI sensitive EGFR mutation status. Diagn. Pathol. 2015, 10, 1-9. [CrossRef] [PubMed]

51. Ito, S.; Kamoto, Y.; Sakai, A.; Sasai, K.; Hayashi, T.; Toyooka, S.; Katayama, H. Unique circulating microRNAs in relation to EGFR mutation status in Japanese smoker male with lung adenocarcinoma. Oncotarget 2017, 8, 114685-114697. [CrossRef] [PubMed]

52. Chen, H.Y.; Yu, S.L.; Chen, C.H.; Chang, G.C.; Chen, C.Y.; Yuan, A.; Cheng, C.L.; Wang, C.H.; Terng, H.J.; Kao, S.F.; et al. A five-gene signature and clinical outcome in non-small-cell lung cancer. N. Engl. J. Med. 2007, 356, 11-20. [CrossRef] [PubMed]

53. Han, J.; Zhao, F.; Zhang, J.; Zhu, H.; Ma, H.; Li, X.; Peng, L.; Sun, J.; Chen, Z. MiR-223 reverses the resistance of EGFR-TKIs through IGF1R/PI3K/Akt signaling pathway. Int. J. Oncol. 2016, 48, 1855-1867. [CrossRef] [PubMed]

54. Cui, R.; Meng, W.; Sun, H.-L.; Kim, T.; Ye, Z.; Fassan, M.; Jeon, Y.-J.; Li, B.; Vicentini, C.; Peng, Y.; et al. MicroRNA-224 promotes tumor progression in non-small cell lung cancer. Proc. Natl. Acad. Sci. USA 2015, 112, 4288-4297. [CrossRef] [PubMed]

55. Hirsch, F.R.; Varella-Garcia, M.; Bunn, P.A.; Di Maria, M.V.; Veve, R.; Bremnes, R.M.; Barón, A.E.; Zeng, C.; Franklin, W.A. Epidermal growth factor receptor in non-small-cell lung carcinomas: Correlation between gene copy number and protein expression and impact on prognosis. J. Clin. Oncol. 2003, 21, 3798-3807. [CrossRef] [PubMed]

56. Bethune, G.; Bethune, D.; Ridgway, N.; Xu, Z. Epidermal growth factor receptor (EGFR) in lung cancer: An overview and update. J. Thorac. Dis. 2010, 2, 48-51. [PubMed]

57. Rikova, K.; Guo, A.; Zeng, Q.; Possemato, A.; Yu, J.; Haack, H.; Nardone, J.; Lee, K.; Reeves, C.; Li, Y.; et al. Global survey of phosphotyrosine signaling identifies oncogenic kinases in lung cancer. Cell 2007, 131, 1190-1203. [CrossRef] [PubMed]

58. Wee, P.; Wang, Z. Epidermal growth factor receptor cell proliferation signaling pathways. Cancers (Basel) 2017, 9, 1-45.

59. Chaib, I.; Karachaliou, N.; Pilotto, S.; Codony Servat, J.; Cai, X.; Li, X.; Drozdowskyj, A.; Servat, C.C.; Yang, J.; $\mathrm{Hu}, \mathrm{C}$; ; et al. Co-activation of STAT3 and YES-associated protein 1 (YAP1) pathway in EGFR-mutant NSCLC. J. Natl. Cancer Inst. 2017, 109, 1-12. [CrossRef] [PubMed]

60. Pan, D. The hippo signaling pathway in development and cancer. Dev. Cell 2010, 19, 491-505. [CrossRef] [PubMed] 
61. He, C.; Mao, D.; Hua, G.; Lv, X.; Chen, X.; Angeletti, P.C.; Dong, J.; Remmenga, S.W.; Rodabaugh, K.J.; Zhou, J.; et al. The Hippo/YAP pathway interacts with EGFR signaling and HPV oncoproteins to regulate cervical cancer progression. EMBO Mol. Med. 2015, 7, 1426-1449. [CrossRef] [PubMed]

62. Yatabe, Y.; Takahashi, T.; Mitsudomi, T. Epidermal growth factor receptor gene amplification is acquired in association with tumor progression of EGFR-mutated lung cancer. Cancer Res. 2008, 68, $2106-2111$. [CrossRef] [PubMed]

63. Lim, L.P.; Lau, N.C.; Garrett-Engele, P.; Grimson, A.; Schelter, J.M.; Castle, J.; Bartel, D.P.; Linsley, P.S.; Johnson, J.M. Microarray analysis shows that some microRNAs downregulate large numbers of target mRNAs. Nature 2005, 433, 769-773. [CrossRef] [PubMed]

64. Fu, J.; Tang, W.; Du, P.; Wang, G.; Chen, W.; Li, J.; Zhu, Y.; Gao, J.; Cui, L. Identifying microRNA-mRNA regulatory network in colorectal cancer by a combination of expression profile and bioinformatics analysis. BMC Syst. Biol. 2012, 6. [CrossRef] [PubMed]

65. Ma, L.; Huang, Y.; Zhu, W.; Zhou, S.; Zhou, J.; Zeng, F.; Liu, X.; Zhang, Y.; Yu, J. An integrated analysis of miRNA and mRNA expressions in non-small cell lung cancers. PLoS ONE 2011, 6, e0026502. [CrossRef] [PubMed]

66. Bass, A.J.; Thorsson, V.; Shmulevich, I.; Reynolds, S.M.; Miller, M.; Bernard, B.; Hinoue, T.; Laird, P.W.; Curtis, C.; Shen, H.; et al. Comprehensive molecular characterization of gastric adenocarcinoma. Nature 2014, 513, 202-209. [CrossRef] [PubMed]

67. Zhong, X.; Luo, G.; Zhou, X.; Luo, W.; Wu, X.; Zhong, R.; Wang, Y.; Xu, F.; Wang, J. Rad51 in regulating the radiosensitivity of non-small cell lung cancer with different epidermal growth factor receptor mutation status. Thorac. Cancer 2016, 7, 50-60. [CrossRef] [PubMed]

(C) 2018 by the authors. Licensee MDPI, Basel, Switzerland. This article is an open access article distributed under the terms and conditions of the Creative Commons Attribution (CC BY) license (http:/ / creativecommons.org/licenses/by/4.0/). 